\title{
On the precision of Calvo parameter estimates in structural NKPC models *
}

\author{
Jean-Marie Dufour ${ }^{\dagger}$ \\ McGill University
}

\author{
Lynda Khalaf $\ddagger$ \\ Carleton University
}

\author{
Maral Kichian $\S$ \\ Bank of Canada
}

July 2009

\footnotetext{
*The authors thank Jordi Galí, seminar participants at the Bank of Canada and Carleton University, the Editors Herbert Dawid and Willi Semmler, and two anonymous referees for several helpful suggestions and comments. Timothy Grieder provided valuable research assistance. This work was supported by the Bank of Canada Research Fellowship Program, the William Dow Chair in Political Economy (McGill University), the Canada Research Chair Program (Econometrics, Université de Montréal, and Environment, Université Laval), the Institut de Finance Mathématique de Montréal (IFM2), the Alexander-von-Humboldt Foundation (Germany), the Canadian Network of Centres of Excellence (program on Mathematics of Information Technology and Complex Systems [MITACS]), the Natural Sciences and Engineering Research Council of Canada, the Social Sciences and Humanities Research Council of Canada, and the Fonds de Recherche sur la Société et la Culture (Québec). The views in this paper are our own and do not necessarily reflect those of the Bank of Canada.

${ }^{\dagger}$ William Dow Professor of Economics, McGill University, Centre interuniversitaire de recherche en analyse des organisations (CIRANO), and Centre interuniversitaire de recherche en économie quantitative (CIREQ). Mailing address: Department of Economics, McGill University, Leacock Building, Room 519, 855 Sherbrooke Street West, Montréal, Québec H3A 2T7, Canada. TEL: (1) 514398 8879; FAX: (1) 514398 4938; e-mail: jean-marie.dufour@mcgill.ca. Web page: http://www.jeanmariedufour.com

${ }^{\ddagger}$ Economics Department, Carleton University, Centre interuniversitaire de recherche en économie quantitative (CIREQ), and Groupe de recherche en économie de l'énergie, de l'environnement et des ressources naturelles (GREEN), Université Laval. Mailing address: Economics Department, Carleton University, Loeb Building 1125 Colonel By Drive, Ottawa, Ontario, K1S 5B6 Canada. Tel (613) 520-2600-8697; FAX: (613)-520-3906. email: Lynda_Khalaf@ carleton.ca.

${ }^{\S}$ Canadian Economic Analysis Department, Bank of Canada, Ottawa, Canada. TEL: (613) 782 7460; FAX: (613) 782 7163; email: mkichian@bankofcanada.ca.
} 


\begin{abstract}
In this paper, we study the extent of empirical information that can be obtained from alternative structural New Keynesian inflation equations regarding the average duration of prices in the United States. Using four illustrative structural equations drawn from the class of indexation and real-wage-rigidity-based models, we evaluate the precision of Calvo parameter estimates. We emphasize the fact that the specifications under consideration may be hard to identify from available data, while errors-in-variables and weak instrument difficulties are unavoidable. In contrast with previous work using identification-robust methods that seems to challenge NKPC models, our results show that all of the models can deliver useful information (albeit to varying degrees) on selected features of inflation dynamics. We also find that results are sensitive to instrument and calibration selection. Conditional on these, we generally find confidence bounds on average duration of price estimates that line up with available micro-founded studies, statistically-significant coefficients for the forcing variables, and non-zero estimates on the coefficient of lag inflation where relevant. With regard to instrument choice, we find that limiting the set of instruments to lagged values of only the variables that appear in the equation of interest can lead to substantial precision losses, even in the context of a limited-information analysis.
\end{abstract}

JEL classification: E31, C13, C3.

Keywords: Sticky-price model; Calvo parameter; Structural estimation; Weak identification; Weak instruments; Indexation; Real wage. 


\section{Introduction}

Empirical tests of the original Calvo-based New Keynesian Phillips Curve (NKPC) have showed that the model does not track well serial correlation in inflation. This has led to adaptations of the NKPC which provide micro-founded mechanisms to build persistence structurally, as a deep model feature. ${ }^{1}$ The resulting specifications however still raise empirical challenges, including building proxies for aggregates such as the marginal cost, finding valid instrumental variables for estimation purposes, accounting for specification and estimation uncertainties, and developing frameworks that formalize aspects of the underlying calibration in richly-parameterized versions.

Models are typically imperfect, but they can nonetheless be useful story-telling devices or valuable tools for policy analysis. ${ }^{2}$ In this respect, researchers are to some extent less concerned about NKPC model misspecification so long as convincing answers to key substantive questions can be reached through their use. ${ }^{3}$ One such fundamental question is the extent of price rigidity in the economy.

In this paper, we focus on this issue. Making use of two selected classes of Calvo-style NKPC inflation models, we examine whether reliable estimates can be obtained for the structural measure of average duration of prices in the data. The two categories of models are structural setups with Calvo-style infrequent price reoptimization that offer alternative ways of generating inflation inertia. We consider: (i) specifications where all or some firms index their non re-optimized prices to lagged inflation, and (ii) versions that allow for the presence of real wage rigidities in the economy. We evaluate the precision of the models' estimates of the Calvo parameter (that defines the probability that at any point in time firms are not able to re-optimize the prices they charge), which in turn determines the extent and the precision of the estimated average duration of prices in the economy. We also examine the degree of indexation measures (for indexation-based models), the value of the wage rigidity index (for wage-based models), and we analyze, when relevant, the implied estimates for structural persistence parameters. Finally, we assess the significance of forcing variables.

The aforementioned empirical issues specific to the NKPC suggest that, in answering the above questions, problems such as errors-in-variables, underidentification, weak instruments, and specification concerns are unavoidable. Furthermore, it is quite difficult to deal with these econometric problems simultaneously and convincingly using traditional estimation methods. ${ }^{4}$ At the same time, econometric methods catering

\footnotetext{
${ }^{1}$ Ball (1994), Fuhrer and Moore (1995) and Roberts (1997) were among the first to point out that the original NKPC specification could not account for some stylized facts about US inflation. A review of theory and evidence about the NKPC can also be found in Woodford (2003).

${ }^{2} \mathrm{~A}$ vast number of models incorporating NKPC equations have been proposed for policy analysis. Some examples are Gali, Lopez-Salido, and Valles (2003), Christiano, Eichenbaum, and Evans (2005), Gali and Monacelli (2005), Smets and Wouters (2007), Lubik and Schorfheide (2007), Jondeau and Sahuc (2008), Rotemberg and Woodford (1997), Boivin and Giannoni (2006), and Del Negro, Schorfheide, Smets, and Wouters (2007).

${ }^{3}$ Indeed, suggestions have been made to formalize this trade-off; see, for example, Del Negro and Schorfheide (2005), Del Negro and Schorfheide (2006), Del Negro, Schorfheide, Smets, and Wouters (2007), as well as the related comment papers and the references cited therein.

${ }^{4}$ For comprehensive surveys on dealing with some of these issues in the presence of identification problems, see Stock, Wright, and Yogo (2002) and Dufour (2003). See also Dufour (1997), Staiger and Stock (1997), Wang and Zivot (1998), Zivot, Startz, and Nelson (1998), Dufour and Jasiak (2001), Kleibergen (2002), Kleibergen (2005), Dufour and Taamouti (2005), Dufour and Taamouti (2007), Andrews, Moreira, and Stock (2006), Hoogerheide, Kaashoek, and van Dijk (2007), Joseph and Kiviet (2005), Kiviet and Niemczyk (2007), Bolduc, Khalaf, and Moyneur (2008), Beaulieu, Dufour, and Khalaf (2008) and Chaudhuri and Zivot
} 
to weak-instruments problems have been gaining credibility in macroeconomics largely due to their focus on the NKPC..$^{5}$ The findings from the latter suggest that data may be weakly informative on key NKPC parameters, which may cast doubt on many commonly held paradigms in this literature.

We therefore make use of identification-robust methods (see the references in footnotes 4 and 5) which are particularly well-suited to conduct structural estimations and testing in our context. These methods are valid whatever the identification status of the examined model, an advantage not shared by standard methodof-moments techniques. As a result, we can find out how well a particular structural parameter is identified, and, what the "true" (i.e., the reliably-assessed) uncertainty associated with its estimate is if the parameter is weakly-identified. Also, these methods can both correct for errors-in-variables, and formally account for the integration of calibration with estimation.

We estimate four structural inflation equations [two specifications based on Eichenbaum and Fisher (2007), the Blanchard and Gali (2007) model, and the Blanchard and Gali (2009) specification], ensuring that the precise form of the econometric model, including aspects such as specification, normalization and parameterization, lines up properly with our question of interest. In this respect, we propose economicallyrelevant instrument sets and econometric specifications that improve overall identification. Additional contributions are that we estimate both the Blanchard and Gali (2007) and the Blanchard and Gali (2009) models structurally, to our knowledge the former having only been estimated in reduced-form, and the latter not having been estimated previously. ${ }^{6}$

Our main results can be summarized as follows. In contrast with previous work using identificationrobust methods that seem to challenge NKPC models, we conclude that: (i) macroeconomic data can actually reveal useful information on average price duration in the economy; (ii) results are nevertheless sensitive to selected instrument and calibration selection. Our findings thus illustrate the limits of testing such models in the absence of theory-based guidance for instrument selection and the difficulties associated with calibration. These issues notwithstanding, we find that several substantive questions can be answered reliably (albeit to varying degrees) with all of the models considered.

Particularly, we find that conditional on selected instruments and calibrations, all of the models can deliver: (i) confidence bounds on the Calvo parameter, and thus on the average duration of prices, that for the latter line up with available micro-founded studies; (ii) generally statistically significant estimates (at usual levels) for the forcing variables; and (iii) non-zero estimates of the structural persistence parameter (i.e., the implied coefficient on lag one inflation) when such effects are not already calibrated-in. These results are obtained when, in general, rather than restricting instruments to the lags of each model's endogenous variables (although admittedly this is a common practice), the lags of the endogenous variables from all considered models are used as instruments for each model. Aside from reflecting difficulties arising from instrumentation, our results call attention to the drawbacks of a strictly limited-information econometric (2008).

${ }^{5}$ Studies having examined the identification issue in NKPC models include Ma (2002), Mavroeidis (2004), Mavroeidis (2005), Dufour, Khalaf, and Kichian (2006), Canova and Sala (2009), Nason and Smith (2008), as well as Kleibergen and Mavroeidis (2009). Related issues may also arise due to structural instability. Indeed Benati (2008) provides evidence that inflation persistence has changed over time.

${ }^{6} \mathrm{~A}$ recent study by Benati (2009) considers a gap-based version of the inflation/unemployment equation by Blanchard and Gali (2007). 
analysis.

In the next section we present the structural forms of the alternative NKPC models examined. Section 3 describes our empirical analysis and discusses the results. Section 4 offers some conclusions. A technical Appendix is included to provide details on the calibrated parameters and on the description of the methodology used in this paper.

\section{Alternative NKPC models}

A number of approaches have been proposed in the literature to build inflation persistence into DSGE models in a structural manner. These include models that focus on different imperfections of the labor market [for examples, see Danthine and Kurmann (2004), Walsh (2005), Krause, Lopez-Salido, and Lubik (2008)], specifications that utilize the concept of infrequent information-updating [otherwise known as sticky information models, see Mankiw and Reis 2002], staggered wage models where wage-setters care about real relative wages [Fuhrer and Moore (1995)], models with indexation of non-optimized prices to lagged aggregate inflation [as in Christiano, Eichenbaum, and Evans (2005)], as well as models that allow for some rigidity in real wages (see section below).

We focus in this paper on the last two model categories, namely indexation-based specifications and models with real wage rigidities. We study four illustrative cases, two from each class. For clarity and ease of exposition, we present these models in their econometric forms, assuming rational expectations. Estimated parameters are introduced in the present section, whereas details on calibrated parameters are discussed in a technical Appendix. We use the following notation: $\hat{\pi}_{t}$ refers to inflation; $s_{t}$ represents real marginal costs; $\beta$ is the subjective discount rate; $\theta$ denotes the Calvo parameter that measures price re-optimization probability and $1 /(1-\theta)$ captures the average duration of prices; $\Delta$ is the first difference operator; $\hat{x}$ is the variable $x$ in deviation from its steady-state value; for all models, the vector of calibrated parameters is denoted by $\varpi$. In line with our general objective, our notation aims to clearly pinpoint the terms within each NKPC where $\theta$ enters explicitly.

\subsection{Indexation-based NKPC models}

Indexation models typically assume that some (partial-indexation) or all (full-indexation) of the firms that do not reoptimize their price adjust the latter to past aggregate inflation. ${ }^{7}$ We consider a set-up based on Eichenbaum and Fisher (2007) and allow for full and partial indexation.

Formally, the model proposes a Calvo (1983) staggered price setting mechanism where, in any given period, each firm has a probability $(1-\theta)$ of resetting its price: i.e., a fraction $(1-\theta)$ of firms can adjust their prices. A proportion $\nu$ of firms are also assumed to update their non-reoptimized prices to lagged inflation. When $\nu=1$, full-indexation is obtained (this is the maintained assumption in Eichenbaum and Fisher 2007). Benchmark DSGE models often also assume that monopolistically competitive firms face a constant elasticity of demand, and that capital is homogenous. Eichenbaum and Fisher (2007) modify this setup to render the last two assumptions more general (and possibly more realistic): (i) they allow firms to face an

\footnotetext{
${ }^{7}$ See, for example, Christiano, Eichenbaum, and Evans (2005) and Smets and Wouters (2003).
} 
increasing price elasticity of demand, by making use of a Kimball (1995) type aggregator over intermediate goods rather than a Dixit-Stiglitz specification; (ii) they allow capital to be firm-specific (as in Sbordonne 2002 and Woodford 2003), adjustable with cost and with some delay. Finally, they assume that price decisions are made subject to the same timing constraints as capital decisions, and that the implementation delay (i.e., the number of periods taken from the time the re-optimization decision is made to the time the actual change is implemented) equals $\tau$ periods. The econometric version of the log-linearized model is given for inflation by:

$$
\hat{\pi}_{t}=\frac{\beta}{(1+\beta \nu)} \hat{\pi}_{t+1}+\frac{\nu}{(1+\beta \nu)} \hat{\pi}_{t-1}+\left[\frac{A(\varpi) D(\beta, \theta, \varpi)}{(1+\beta \nu)}\right] \lambda(\beta, \theta) \hat{s}_{t}+e_{1, t+1}
$$

where

$$
\lambda(\beta, \theta)=\frac{(1-\theta)(1-\beta \theta)}{\theta} .
$$

The model expresses inflation (in deviation from steady-state) as a function of expected and past inflation, as well as of real marginal costs $\left(\hat{s}_{t}\right){ }^{8}$ The error term $e_{1, t+1}$ is a moving average of order $\tau$ that represents the assumed implementation delay. As for the functions $A(\varpi)$ and $D(\beta, \theta, \varpi)$, they refer to the structural assumptions regarding the price elasticity of intermediate goods' demand that firms face, and the type of capital market, respectively (refer to the Appendix for more details). Thus, when capital is homogeneous and firms face a constant price elasticity of demand, $A(\varpi)=D(\beta, \theta, \varpi)=1$. However, if firms face a variable price elasticity of demand, $A<1$, and if capital is firm-specific, then $D<1$.

The latter assumptions, in conjunction with the corresponding calibrations, cause inflation to react less to changes in real marginal costs. Eichenbaum and Fisher (2007) argue that these generalizations are needed in order for the model to imply plausible degrees of inertia in price setting behavior by firms. We revisit this evidence by estimating $\theta$ (the Calvo parameter) and $\nu$ (the degree of indexation) in this model under different calibrations.

\subsection{NKPC models with real wage rigidity}

Recently extensions have been proposed to the standard DSGE setup that suggest a role for unemployment in the determination of inflation by combining nominal rigidities in prices and wages with various other types of labor market frictions (including, for example, search and matching effects). Among these are models with real wage rigidities that specify the joint evolution of prices and wages, and where the interaction between labor market imperfections and inflation can be captured via formal assumptions regarding the dynamics of marginal costs. This class of models is somewhat different from the indexation class of models which primarily assume flexible wages and focus mainly on price dynamics, and where real marginal costs simply correspond to unit labor costs.

The two illustrative models that we retain as part of the real-wage-rigidity-based class are the recent Blanchard and Gali (2007) and the Blanchard and Gali (2009) specifications. The Blanchard and Gali (2007)

\footnotetext{
${ }^{8}$ To be more specific, $\hat{\pi}_{t}=\pi_{t}-\mu_{\pi}$, where $\pi_{t}$ is the inflation rate and $\mu_{\pi}$ its steady-state value, while $\hat{s_{t}}=s_{t}-\mu_{s}$ where $s_{t}$ is is the real marginal cost and $\mu_{s}$ its steady-state value. In the following empirical analysis, the steady-state values will be taken as unknown but stationary, so they can be viewed as unknown constants. On gathering all the constant terms, the unknown stationary values can be accounted by including a constant term in the model.
} 
model considers staggered Calvo pricing and makes the assumption that, as a result of some (non-specified) market imperfection, real wages respond sluggishly to labor demand conditions. An index of real wage rigidity, $\gamma$, is proposed whereby higher values for this parameter means real wages depend more on lagged wages. The econometric version of this model is given by:

$$
\hat{\pi}_{t}=\frac{\beta}{1+\beta} \hat{\pi}_{t+1}+\frac{1}{1+\beta} \hat{\pi}_{t-1}-\left[\frac{(1-\gamma) B(\varpi)}{\gamma(1+\beta)}\right] \lambda(\beta, \theta) \hat{U}_{t}+\left[\frac{G(\varpi)}{(1+\beta)}\right] \lambda(\theta, \beta) \hat{\Delta} v_{t}+e_{2, t+1},
$$

where $\hat{U}_{t}$ is the rate of unemployment, $\hat{\Delta} v_{t}$ is the change in the real price of the non-produced good in the economy (representing an observable equivalent to a supply shock term), and where the error term, which reflects rational expectation error, is uncorrelated with time $t-1$ variables. The functions $B(\varpi)$ and $G(\varpi)$, where $\varpi$ represents the calibrated parameters (see the Appendix for more detail) capture the share of the non-produced good in total output and the slope of labor supply. ${ }^{9}$

The above equation again relates inflation to future and lagged inflation. Inflation also depends on the real price of the non-produced good in the economy, $\hat{\Delta} v_{t}$, that is meant to capture supply-side effects. Finally, unemployment enters the model based on underlying equilibria between marginal costs and the employment gap. In this model, we estimate $\theta$ (the Calvo parameter) and $\gamma$ (the wage rigidity index).

The second model that we consider is that proposed in Blanchard and Gali (2009). In this case, staggered price and nominal wage setting is combined with an articulated set of assumptions regarding frictions in the labor market, along the lines of the search and matching model of Diamond-Mortensen-Pissarides. The latter context implies that productivity shocks affect both unemployment and inflation, which is exploited to derive a relation between inflation and the unemployment rate. The following inflation equation is obtained:

$$
\hat{\pi}_{t}=H_{1}(\varpi) \lambda(\beta, \theta) \hat{U}_{t}+H_{2}(\varpi) \lambda(\beta, \theta) \hat{U}_{t-1}+H_{3}(\beta, \varpi) \lambda(\beta, \theta) \gamma a_{t},
$$

where $a_{t}$ is $\log$ deviations of productivity from its steady-state and is assumed to follow a stationary autoregressive process with a parameter $\rho$ and where $\gamma$ is the index of real wage rigidities. ${ }^{10}$ The variable $\hat{U}_{t}$ is the unemployment rate in deviation from $\bar{U}$ (the steady-state value of unemployment). The functions $H_{1}(\varpi)$, $H_{2}(\varpi)$ and $H_{3}(\beta, \varpi)$ (as defined in the Appendix) capture various labor market characteristics, including the central role of labor market tightness, hiring costs, as well as steady state mark-up. We estimate the model in the following quasi-differenced form:

$$
\hat{\pi}_{t}-\rho \hat{\pi}_{t-1}=H_{1}(\varpi) \lambda(\beta, \theta) \hat{U}_{t}+\left[H_{2}(\varpi)-\rho H_{1}(\varpi)\right] \lambda(\beta, \theta) \hat{U}_{t-1}-\rho H_{2}(\varpi) \lambda(\beta, \theta) \hat{U}_{t-2}+e_{3, t} .
$$

The theoretical relations that deliver the inflation/unemployment equation described by (4) can be summarized as follows. The underlying price setting mechanism takes the typical Calvo form, in which firms choose an optimal price that is a weighted function of current and expected marginal costs where weights depend on $\theta$. Equilibrium leads to the usual NKPC expression for inflation as a function of expected inflation and marginal costs. In turn, marginal costs depend on labor market frictions and on real wage rigidities.

\footnotetext{
${ }^{9}$ In the Blanchard and Gali (2007) specification, the equilibrium model is linearized around a zero steady state. In equation (3), we nevertheless express inflation and unemployment in deviation with respect to (potentially non-zero) unknown equilibrium values. We thus allow for an unrestricted constant in this model as well as in all models studied.

${ }^{10}$ In equation (4), we express inflation in deviation with respect to a (potentially non-zero) equilibrium value. We thus allow for an unrestricted constant in this model conforming with models studied.
} 
Formally, this requires some specification for the marginal cost process, as a function e.g. of labor market tightness (the job-finding rate) and productivity. From there on, the relation between labor market tightness and unemployment leads to the above NKPC, assuming some process for productivity. In this model, we estimate $\theta$ (the Calvo parameter) and $\rho$ (the autoregressive process parameter).

Note that the quasi-differenced equation we estimate does not allow to identify the components of the coefficient on productivity in (4). Nevertheless, the transformation from (4) to (5) implies that both $\lambda(\beta, \theta)$ and $\gamma$ multiply the variance of the error term in (5); a non-zero error variance [a prerequisite for (5) to be estimable] thus requires, in addition to a non-unit $\theta$, a non-zero $\gamma$. The positivity restriction on $\gamma$ is fundamental to the model, since a non-zero $\gamma$ implies that wages do not adjust fully to productivity changes, in which case it becomes impossible to fully stabilize both inflation and unemployment.

\subsection{Main issues}

The models considered rely on different approaches to building persistence, yet all incorporate the Calvo model of price setting. We thus target the Calvo parameter as our key parameter of interest. We also revisit some of the ongoing debates in this literature, arising from conflicts between theoretical predictions and evidence and/or mixed empirical findings. Some of the questions relevant to indexation models that we treat in this paper are the following.

1. Eichenbaum and Fisher (2007) argue, using model (1) with $\nu=1$, that economically plausible estimates of $\theta$ require relaxing the homogenous capital and the constant elasticity of demand assumptions, via a calibration-based adjustment of the $A(\varpi)$ and $D(\beta, \theta, \varpi)$ terms. We revisit the empirical support for this feature.

2. Inflation persistence models has recently been questioned since the parameters that capture persistence have been estimated for many inflation-targeting countries to be fairly small and even insignificant in relatively stable monetary policy regimes; see Benati (2008) and the references therein. In contrast, countries such as the United States were not found to exhibit similar outcomes. Because of the specific structure of the model under consideration, our estimates of the indexation parameter $\nu$ also shed some light on this issue.

3. Whether the data supports full indexation is a worthy empirical question, particularly because this parameter is often calibrated in available published works.

Real-wage-rigidity-based inflation models are relatively more recent than the indexation-based class, so available empirical evidence is more scarce compared to the indexation-based class. In particular, empirical evidence on deep parameters is still lacking. Some of the issues relevant to these models and that we address in this paper are the following.

4. Both models we consider capture a dynamic inflation/unemployment trade-off, the analysis of which constitutes one of the key questions in macroeconomics. We assess how inflation and unemployment 
are related, via the sign as well as the significance of the current level of unemployment in both specifications. ${ }^{11}$ In addition, we underline the differences among the two equations as follows.

(a) Model (3) structurally embeds, in addition to the unemployment level, the change in the real price of the non-produced good in the economy. This term may empirically capture effects such as commodity price changes or other supply side factors that have long been linked to the fit of traditional Phillips-Curves or VAR-based inflation models (refer for example to Consolo, Favero, and Paccagnini (2009) and the references therein for a recent discussion). We assess these effects via the implied coefficient on $\hat{\Delta} v_{t}$ (note its dependence on $\theta$ ).

(b) In contrast, whether labor market frictions are helpful in capturing inflation dynamics depends, in model (5), on both the current level and the change in unemployment. Since $\lambda(\beta, \theta)$ affects all unemployment lags in (5), the ability to statistically refute unrealistically high values of $\theta$ (formally, the boundary value of one) provides a joint test for this fundamental model characteristic. We take this question to the data.

5. In model (4), productivity shocks figure as prominent determinants of inflation. In particular, the more persistent the process for productivity, the more important are its effects on inflation. Indeed, the quasidifferenced transform that we take to the data illustrates the extent of such additional inertia, beyond the dependence on two lags of the unemployment rate. We study the role of productivity shocks via a model-specific estimate for the AR(1) coefficient in the underlying process for productivity.

6. As argued above, and as may be checked from the derivation in the original paper, (3) results from a gap-based relation that takes the familiar hybrid NKPC form. That relation allows for both an inflation lag [with coefficient equal to $\gamma /(1+\beta \gamma)$ ] as well as an expectation term [with coefficient equal to $\beta /(1+\beta \gamma)$ ], and where the driving variable (with coefficient equal to $\lambda(\beta, \theta)$ ) is a linear combination of the current and lagged distance of output from its equilibrium value under flexible prices. While the (3) form is more amenable to estimation than the latter form (because of the usual difficulties associated with measuring the unobserved gap variable), the gap-based version, that hinges on the precision of the estimates of $\gamma$, may also serve to empirically address question (2) above.

\section{Empirical analysis}

\subsection{Data}

We conduct our estimations on quarterly U.S. data for the sample extending from 1982Q3 to 2006Q4. The sample choice is somewhat motivated by the fact that many studies (see, for example, Benati (2008) and the references therein) find evidence of a structural break prior to this date. We use the GDP deflator for the price level, $P_{t}$, the compensation per hour in the non-farm business sector for wages, $W_{t}$, and we define the labor share of income as total compensation paid to employees divided by nominal GDP. We also deflate

\footnotetext{
${ }^{11}$ As formally shown in the Appendix, our method delivers a confidence set that is identification robust, which allows a precise statistical assessment of the coefficient sign.
} 
the producer price of crude materials by the GDP deflator to obtain a measure for the real price of the non-produced good in the economy, $V_{t}$.

Taking the log of these series (which we represent by the corresponding small letters), we define inflation, $\hat{\pi}_{t}$, as $\log \left(P_{t} / P_{t-1}\right)$, real marginal cost, $s_{t}$ as the detrended logarithm of the labor share of income, and the change in the price of the non-produced good, $\hat{\Delta} v_{t}$, as the $\log$ difference in $V_{t}$. In addition, we use the

quarterly U.S. unemployment rate for $\hat{U}_{t}$. Labor productivity is given by the log of the ratio of GDP to employment, where the latter is total non-farm employment.

\subsection{Estimation overview}

We conduct all structural estimations and testing using identification-robust methods. The reasons for relying on such approaches instead of typically-used methods such as standard generalized method of moments (GMM) or maximum likelihood are explained at some length in Mavroeidis (2004), Mavroeidis (2005), Dufour, Khalaf, and Kichian (2006), Canova and Sala (2009), Nason and Smith (2008), Dufour, Khalaf, and Kichian (2008), as well as Kleibergen and Mavroeidis (2009). In the Appendix, we briefly summarize the identification-robust methods that we apply with a rather intuitive emphasis on their validation; we refer the reader to the above references for more information. For presentation clarity, the following characteristics of the applied method deserve notice.

1. In contrast with usual inference methods, first a confidence region of joint level $1-\alpha$ is constructed for the parameters of interest, then a point estimate is found from within this region.

2. The confidence region is constructed sweeping the economically-meaningful values of parameters and collecting those parameter combinations that are not rejected at a certain level $\alpha$ by a specificallydesigned test [refer to (23)].

3. Point estimates correspond to the vector of parameter values that maximize the latter test's $p$-value [refer to (25)], or, alternatively, that is "least-rejected".

4. The confidence region so defined admits the possibility of being both empty [refer to (26)] and unbounded, with the former indicating model misspecification, and the latter, lack of identification. In other words, both a misspecification test and a check for weak identification are hardwired into the set estimation method.

It is also worth noting that the built-in misspecification check may shed light on the dependence structure of model shocks. Recent studies on identification robust method have shown that test rejections may be driven by wrongly using instruments that are correlated with error terms; see Doko-Tchatoka and Dufour 2008. So spurious rejections would occur when, in the data, shocks are uncorrelated with time $t-\bar{\tau}$ information, yet time $t-(\bar{\tau}-1)$ variables are used as instruments. Aside from model (1) with $\tau>1$, time $t-1$ variables are theoretically legitimate instruments. Nevertheless, empirical considerations arising from say measurement errors often justify considering longer dependence orders. For the tests we apply, this suggests relying on time $t-\bar{\tau}$ instruments when confidence sets with time $t-(\bar{\tau}-1)$ lags are empty. 
In what follows, significance refers to a five per cent test level. All variables are taken in deviation from the sample mean, which is in accordance with not fixing steady-state values to specific (zero or non-zero) parameters, but allowing them to be free constants. ${ }^{12}$ In addition, four lags are used in the Newey-West heteroskedasticity and autocorrelation-consistent covariance estimator.

Estimation and test results are reported in Tables 1-3. In the case of each model, we report the point estimates of the structural parameter and associated reduced-form parameters, the implied average duration of prices (in quarters) given by $1 /(1-\theta)$, as well as the test p-value associated with the vector of point estimates [i.e., the maximal p-value from (25)]. In addition, for each estimated parameter, we report in parentheses its smallest and highest values in the confidence set.

We conduct estimations using as instruments lags of the endogenous variables, that is inflation along with the forcing variables from all three models: marginal cost, unemployment rate, and the change in the real price of the non-produced good. For models (1) and (3), we also consider for completion, and for the purpose of comparing our result with the original studies, an instrument set based on model-specific forcing variables (that is, lags of the marginal cost for model (1), and lags of unemployment and the change in the real price of the non-produced good for model (3)).

In the case of model (5) we add lags of productivity to the instrument set in order to identify $\rho$; we report results with and without productivity lags to illustrate inseparability of inference in such models. To avoid the "many instruments" problem ${ }^{13}$, we use two inflation lags and as many lags of the forcing variables. The instrument set specific to model (1) is denoted $Z^{E F}$, that specific to model (3) is referred to as $Z^{B G}$, and the sets including all forcing variables are $Z^{*}$ and $Z^{P}$ (the latter includes also lags of productivity). We hereafter refer to the set that restricts instruments to the lags of each models' own endogenous variable, as the "model-specific" set. In contrast, the full set of instruments we use is denoted as the "extra-model" set.

The instrument set used in the original study on model (1) in Eichenbaum and Fisher (2007) includes lags of each of inflation, marginal costs, output gap, and change in nominal wages. Our estimations with this instrument set produces results that are qualitatively similar to the $Z^{E F}$ case for this model. The instrument set used in the original study on model (3) in Blanchard and Gali (2007) includes four lags of each of inflation, the unemployment rate, and the change in the real price of the non-produced good in the economy (that was proxied by real price of oil by Blanchard and Gali (2007) and that we proxy with the real price of producer price of crude materials). We use only two lags to avoid loss of power and/or spurious rejections. ${ }^{14}$

In the case of model (1), estimation with first, second and third lags of the considered variables lead to model rejection. For model (5), estimation with first and second lags also yield empty confidence sets. As argued above, these results conform with the likely presence of a fairly long moving-average root. In contrast, we find lag $t-1$ variables to be empirically compatible with model (3). While one must guard against over-interpreting such evidence, it is worth noting that model (3) features a crude materials price

\footnotetext{
${ }^{12}$ See Sbordone (2007) for a discussion on the importance of doing so in empirical contexts. In this paper, we follow this approach and allow for an unrestricted constant in the all the empirical specifications studied. Numerically, this can be done by: either (1) using raw (uncentered) variables and adding a constant term in the equations studied, or (2) expressing each variable in deviation with respect to its empirical mean and dropping the constant term. It is easy to see that both these approaches yield the same results.

${ }^{13}$ Refer to Kleibergen and Mavroeidis (2009) and related comments in the same volume by Canova, Chaudhuri and Zivot, Dufour, Mikusheva, Wright and Yogo.

${ }^{14}$ Recall that the Blanchard and Gali (2009) model was not originally estimated.
} 
index; see the recent discussion in Consolo, Favero and Paccagnini (2009) and the references therein on the role of commodity price indices in empirical inflation modeling.

\subsection{Empirical results}

\subsubsection{Indexation-based models}

For model (1), we estimate $\theta$ and the partial indexation parameter $\nu$. The search space for $\theta$ is $(0.02,1.00)$ and for $\nu$ it is $(0.00,1.00)$, with grid increments of 0.02 for both. Table 1 reports the results on this model.

Consider first the cases where the instrument set, $Z^{E F}$, is used. Whether capital is homogeneous or firm-specific, the obtained confidence estimate for $\theta$, although bounded at the lower end, hits a much too high value of 0.98 , implying an implausible 50 quarters for average price duration in the economy. The point estimate for $\theta$ is about 2.27 quarters under homogenous capital and for $A(\varpi)=1$. In line with the arguments of Eichenbaum and Fisher, this estimate is much lower (at around 1.25 quarters) when the more general assumptions of firm-specific capital and $A(\varpi)<1$ are made (the resulting value for $D(\beta, \theta, \varpi)$ is 0.44 in this case). Notice, also, that the coefficient estimate on real marginal cost is almost zero regardless of the assumptions on $A(\varpi)$ and capital.

As soon as we consider the other instrument set $Z^{*}$ (that was not considered in the original studies) results change importantly. In particular, we find the Calvo parameter to be bounded at both the upper and lower ends. Under homogenous capital and $A(\varpi)=1$, the point estimate for $\theta$ is 0.46 , corresponding to an average price duration of 1.85 quarters, with the projections indicating a lower bound of 1.56 and an upper bound of 2.63 . When both $A(\varpi)$ and $D(\beta, \theta, \varpi)$ are calibrated to be $<1$, the estimate is 0.12 , implying an average price duration of approximately 1.14 quarters. Indeed, one might argue that this number is too low, given that micro-based studies suggest ranges of around 1.7-1.8 quarters. ${ }^{15}$ The projected bounds for $\theta$ also turn out to be lower, with a range of 0.08 to 0.24 , implying 1.09 to 1.31 quarters for average price durations.

Furthermore, with $Z^{*}$, the coefficient on real marginal costs is significant (economically and statistically), with a point estimate of 0.32 when $A(\varpi)=D(\beta, \theta, \varpi)=1$ and a projection range of approximately 0.13 to 0.60 . Estimates on this parameter are almost unchanged when $A(\varpi)$ and $D(\beta, \theta, \varpi)$ are calibrated to be $<1$. These results point to an important role for the extra-model instruments that include the lagged forcing variables associated with the real wage rigidity based equations: lagged unemployment rate and lagged change in the real price of the non-produced good.

Regarding the indexation parameter, our results are qualitatively invariant to all considered calibrations and instruments. We find that: (i) the zero value is firmly ruled out for $v$ with estimates quite far from zero (the lowest estimated bound is 0.40 ); and (ii) all obtained confidence intervals cover the $v=1$ value. This result sheds light on the backward-looking behavior of the NKPC, which we discuss further in Section 3.4 below.

\footnotetext{
${ }^{15}$ For example, see Bils and Klenow (2004) and Klenow and Kryvtsov (2008). Note that even though macroeconomic models are admitted simplifications entailed by aggregate behavior (see, for instance, the discussion in Sims (2007)), it is nonetheless expected that estimates from NKPC models should more-or-less line up with the micro-based evidence.
} 


\subsubsection{Models with wage rigidity}

For the Blanchard and Gali (2007) model, we structurally estimate $\theta$ and the real wage rigidity index $\gamma$. The search space for $\theta$ is again $(0.02,1.00)$ and it is $(0.02,1.00)$ for $\gamma$, with grid increments of 0.02 in both cases.

Table 2 reports structural estimation and test results for this model. We note that in contrast with the indexation-based model, and although results remain sensitive to the calibration considered, we find wellbounded confidence sets for $\theta$ for all considered calibrations and instrument sets. Using extra-model instruments yields tighter confidence intervals. When $\mu=1.00$ and $v=0.33$, we find a point of estimate of 0.58 with the model-specific instruments, and 0.64 with extra-model instruments. The projections for the average duration of prices range from 1.85 to 3.57 quarters with the former set, and from 2.63 to 2.94 with the latter set. Both point and set estimates imply a lower average duration of prices when we set $\mu=0.50$ and $v=0.05$ : the upper bound is 1.79 quarters with the model-specific instruments and 1.56 quarters with extra-model instruments.

A key feature that results from reliance on the extra-model instrument concerns the significance of the implied coefficient of current unemployment. Indeed, under both calibrations, the projection for this parameter does not rule out zero when the model-specific instruments are used. In contrast, the coefficient is significant when the expanded instruments set is used. These results point to an important role for the lagged marginal cost variable in identifying the inflation/unemployment trade-off embodied by (3).

We also find that the coefficient on $\hat{\Delta} v_{t}$ is correctly signed and significant. This result is worth noting particularly because it is invariant to our calibrations and considered instruments.

Regarding the wage rigidity index, our analysis reveals another finding that is invariant to calibration and instruments: the projections for $\gamma$ decisively exclude zero, and estimates are not close to zero (the lowest observed lower limit is 0.42 ). We note nevertheless that, as with the coefficient on time $t$ unemployment, the extra-model instrument set yields tighter confidence sets for this parameter, ruling out the unit boundary for both considered calibrations. In addition, except with the model-specific set and the $\mu=1.00$ and $v=0.33$ calibration, we find that real wages are mostly backward-looking, as the lowest boundary for the $\gamma$ estimate exceeds 0.50 .

Results for the last model that we examine (Blanchard and Gali (2009)) are reported in Table 3. In this case, we estimate structurally the parameter $\theta$ and the coefficient $\rho$, imposing stationarity and using an expanded instrument set that now includes also lags of productivity. Note that our empirical specification allows $\gamma$ to be a free non-zero parameter (that scales the error term). The range for the estimated $\theta$ is again $(0.02,1.00)$, and for $\rho$ it is $(0.85,0.99)$, while the grid search increment is 0.02 for the former, and 0.01 for the latter.

Results pertaining to $\theta$ correspond closely to what we observe with the indexation-based model, in that they depend dramatically on the chosen instrument set. Thus, when productivity is not considered in the information set, recovered confidence intervals on both $\theta$ and $\rho$ are much more diffuse, and hit the unrealistic 0.98 boundary for $\theta$. In contrast, the use of productivity (which makes sense when attempting to estimate $\rho$ ) tightens estimated sets for both parameters, dramatically in the case of $\theta$, leading to economically-reasonable values for the average duration of prices that range from 1.67 to 2.12 or to 2.72 depending on the calibration. Our results highlight the non-separability of inference in such highly non-linear models. 
Table 1. Indexation model: estimation and tests

\begin{tabular}{|c|c|c|c|c|c|c|c|}
\hline & \multicolumn{2}{|c|}{ Estimates } & \multicolumn{4}{|c|}{ Implied Estimates } & \multirow[b]{2}{*}{ Max P-va } \\
\hline Inst. & $\nu$ & $\theta$ & $1 /(1-\theta)$ & coef. on $\hat{\pi}_{t+1}$ & coef. on $\hat{s_{t}}$ & coef. on $\hat{\pi}_{t-1}$ & \\
\hline \multicolumn{8}{|c|}{$A(\varpi)=1 ; D(\beta, \theta, \varpi)=1$} \\
\hline$Z^{E F}$ & $\begin{array}{c}1.00 \\
(0.68,1.00)\end{array}$ & $\begin{array}{c}0.56 \\
(0.42,0.98)\end{array}$ & $\begin{array}{c}2.27 \\
(1.72,50.0)\end{array}$ & $\begin{array}{c}0.50 \\
(0.50,0.59)\end{array}$ & $\begin{array}{c}0.18 \\
(0.0003,0.41)\end{array}$ & $\begin{array}{c}0.50 \\
(0.41,0.50)\end{array}$ & 0.1129 \\
\hline$Z^{*}$ & $\begin{array}{c}1.00 \\
(0.40,1.00)\end{array}$ & $\begin{array}{c}0.46 \\
(0.36,0.62)\end{array}$ & $\begin{array}{c}1.85 \\
(1.56,2.63)\end{array}$ & $\begin{array}{c}0.50 \\
(0.50,0.71)\end{array}$ & $\begin{array}{c}0.32 \\
(0.13,0.60)\end{array}$ & $\begin{array}{c}0.50 \\
(0.29,0.50)\end{array}$ & 0.2048 \\
\hline \multicolumn{8}{|c|}{$A(\varpi)=0.23 ; D(\beta, \theta, \varpi)<1$} \\
\hline$Z^{E F}$ & $\begin{array}{c}1.00 \\
(0.68,1.00)\end{array}$ & $\begin{array}{c}0.20 \\
(0.12,0.98)\end{array}$ & $\begin{array}{c}1.25 \\
(1.13,50)\end{array}$ & $\begin{array}{c}0.50 \\
(0.50,0.59)\end{array}$ & $\begin{array}{c}0.17 \\
(0.0001,0.34)\end{array}$ & $\begin{array}{c}0.50 \\
(0.41,0.50)\end{array}$ & 0.1126 \\
\hline$Z^{*}$ & $\begin{array}{c}1.00 \\
(0.40,1.00)\end{array}$ & $\begin{array}{c}0.12 \\
(0.08,0.24)\end{array}$ & $\begin{array}{c}1.14 \\
(1.09,1.31)\end{array}$ & $\begin{array}{c}0.50 \\
(0.50,0.71)\end{array}$ & $\begin{array}{c}0.33 \\
(0.13,0.58)\end{array}$ & $\begin{array}{c}0.50 \\
(0.29,0.50)\end{array}$ & 0.2056 \\
\hline
\end{tabular}

The estimated model is ( 1$)$ :

$$
\hat{\pi}_{t}=\frac{\beta}{(1+\beta \nu)} \hat{\pi}_{t+1}+\frac{\nu}{(1+\beta \nu)} \hat{\pi}_{t-1}+\left[\frac{A(\varpi) D(\beta, \theta, \varpi)}{(1+\beta \nu)}\right] \lambda(\beta, \theta) \hat{s}_{t}+e_{1, t+1} .
$$

The applied test is the AR-HAC test. Four lags are used in the Newey-West heteroskedasticity and autocorrelation-consistent covariance estimator. Hodges-Lehmann point estimates are reported with the corresponding $p$-value under the heading 'Max P-val', while $1 /(1-\theta)$ refers to the average duration of prices (in quarters). The numbers in parentheses reported underneath a parameter estimate correspond to the projection-based confidence interval for that parameter. Instrument sets are as follows: $Z^{E F}$ includes the fourth and fifth lag of each of: inflation and marginal cost. $Z^{*}$ includes the fourth and fifth lags of each of inflation, marginal costs, the unemployment rate, and the change in the real price of the non-produced good in the economy.

In addition, regardless of the calibration used, when productivity is excluded from the instrument set, estimated ranges for current and lag one unemployment are, although significant, close to the boundary; the estimate for the second lag term practically hits the zero boundary. In contrast, when productivity is considered in the instrument set, coefficient estimates of the implied reduced-form parameters are significant and have the right sign. Our estimated sets for $\rho$ also sharpen when productivity is used, for both considered calibrations. The estimated range signals high persistence; on recalling that we imposed stationarity in line with the underlying theoretical model, we note that the boundary 0.99 value cannot be ruled out.

\subsection{Discussion}

The results obtained above provide the following insights regarding the main issues raised in section 2.3.

On question 1, as pointed out by Eichenbaum and Fisher (2007), making the double assumptions that capital is firm-specific and that intermediate good firms face a variable price elasticity of demand, lowers the estimated value of average price duration. Our finding with the model consistent instrument set conforms with Eichenbaum and Fischer's arguments. However, upon allowing for extra-model instruments, we find that estimates of $\theta$ that line up with micro-based evidence can be obtained even for the $A(\varpi)=D(\beta, \theta, \varpi)=1$ 
Table 2. Blanchard-Gali (2007) model: estimation and tests

\begin{tabular}{|c|c|c|c|c|c|c|c|}
\hline & \multicolumn{2}{|c|}{ Estimates } & \multicolumn{4}{|c|}{ Implied Estimates } & \multirow[b]{2}{*}{ Max P-val } \\
\hline Inst. & $\gamma$ & $\theta$ & $1 /(1-\theta)$ & coef. of $\hat{U}_{t}$ & coef. of $\hat{\Delta} v_{t}$ & $\gamma /(1+\beta \gamma)$ & \\
\hline \multicolumn{8}{|c|}{$\mu=1.00 ; v=0.33$} \\
\hline$Z^{B G}$ & $\begin{array}{c}0.88 \\
(0.42,1.00)\end{array}$ & $\begin{array}{c}0.58 \\
(0.46,0.72)\end{array}$ & $\begin{array}{c}2.38 \\
(1.85,3.57)\end{array}$ & $\begin{array}{c}-0.01 \\
(-0.10,0.00)\end{array}$ & $\begin{array}{c}0.05 \\
(0.02,0.11)\end{array}$ & $\begin{array}{c}0.47 \\
(0.30,0.50)\end{array}$ & 0.2458 \\
\hline$Z^{*}$ & $\begin{array}{c}0.68 \\
(0.54,0.84) \\
\end{array}$ & $\begin{array}{c}0.64 \\
(0.62,0.66) \\
\end{array}$ & $\begin{array}{c}2.78 \\
(2.63,2.94) \\
\end{array}$ & $\begin{array}{c}-0.03 \\
(-0.05,-0.01) \\
\end{array}$ & $\begin{array}{c}0.03 \\
(0.03,0.04) \\
\end{array}$ & $\begin{array}{c}0.41 \\
(0.35,0.46) \\
\end{array}$ & 0.0596 \\
\hline \multicolumn{8}{|c|}{$\mu=0.50 ; v=0.050$} \\
\hline$Z^{B G}$ & $\begin{array}{c}0.96 \\
(0.78,1.00)\end{array}$ & $\begin{array}{c}0.28 \\
(0.16,0.44)\end{array}$ & $\begin{array}{c}1.39 \\
(1.19,1.79)\end{array}$ & $\begin{array}{c}-0.02 \\
(-0.11,0.00)\end{array}$ & $\begin{array}{c}0.05 \\
(0.02,0.11)\end{array}$ & $\begin{array}{c}0.49 \\
(0.44,0.50)\end{array}$ & 0.2411 \\
\hline$Z^{*}$ & $\begin{array}{c}0.90 \\
(0.86,0.96)\end{array}$ & $\begin{array}{c}0.34 \\
(0.30,0.36)\end{array}$ & $\begin{array}{c}1.52 \\
(1.43,1.56)\end{array}$ & $\begin{array}{c}-0.03 \\
(-0.05,-0.01)\end{array}$ & $\begin{array}{c}0.03 \\
(0.03,0.04)\end{array}$ & $\begin{array}{c}0.46 \\
(0.46,0.49)\end{array}$ & 0.0594 \\
\hline
\end{tabular}

The estimated model is (3)

$$
\hat{\pi}_{t}=\frac{\beta}{1+\beta} \hat{\pi}_{t+1}+\frac{1}{1+\beta} \hat{\pi}_{t-1}-\left[\frac{(1-\gamma) B(\varpi)}{\gamma(1+\beta)}\right] \lambda(\beta, \theta) \hat{U}_{t}+\left[\frac{G(\varpi)}{(1+\beta)}\right] \lambda(\theta, \beta) \hat{\Delta} v_{t}+e_{2, t+1} .
$$

The applied test is the AR-HAC test. Four lags are used in the Newey-West heteroskedasticity and autocorrelation-consistent covariance estimator. Hodges-Lehmann point estimates are reported with the corresponding $p$-value under the heading 'Max P-val', while $1 /(1-\theta)$ refers to the implied average duration of prices (in quarters). The numbers in parentheses reported underneath a parameter estimate correspond to the projection-based confidence interval for that parameter. Instrument sets are as follows: $Z^{B G}$ includes includes the second and third lags of inflation, and the first, second and third lags of each of the unemployment rate, and the change in the real price of the non-produced good in the economy. $Z^{*}$ includes the second and third lags of inflation, and the first, second and third lags of each of the unemployment rate, the marginal cost and the change in the real price of the non-produced good in the economy. 
Table 3. Blanchard-Gali (2009) model: estimation and tests

\begin{tabular}{|c|c|c|c|c|c|c|c|}
\hline & \multicolumn{2}{|c|}{ Estimates } & \multicolumn{4}{|c|}{ Implied Estimates } & \multirow[b]{2}{*}{ Max P-val } \\
\hline Inst. & $\rho$ & $\theta$ & $1 /(1-\theta)$ & coef. of $\hat{U}_{t}$ & coef. of $\hat{U}_{t-1}$ & coef. of $\hat{U}_{t-2}$ & \\
\hline \multicolumn{8}{|c|}{$\tilde{\alpha}=1 ; \tilde{\delta}=0.12 ; x=0.70 ; M=1.20 ; B=0.11$} \\
\hline$Z^{*}$ & $\begin{array}{c}0.91 \\
(0.85,0.99)\end{array}$ & $\begin{array}{c}0.42 \\
(0.28,0.98)\end{array}$ & $\begin{array}{c}1.72 \\
(1.38,50.0)\end{array}$ & $\begin{array}{c}-0.65 \\
(-1.50,-0.001)\end{array}$ & $\begin{array}{c}0.77 \\
(0.001,1.87)\end{array}$ & $\begin{array}{c}-0.16 \\
(-0.39,-0.00)\end{array}$ & 0.0943 \\
\hline$Z^{P}$ & $\begin{array}{c}0.99 \\
(0.91,0.99)\end{array}$ & $\begin{array}{c}0.46 \\
(0.40,0.56)\end{array}$ & $\begin{array}{c}1.85 \\
(1.67,2.72)\end{array}$ & $\begin{array}{c}-0.52 \\
(-0.73,-0.28)\end{array}$ & $\begin{array}{c}0.59 \\
(0.32,0.89)\end{array}$ & $\begin{array}{c}-0.12 \\
(-0.18,-0.06)\end{array}$ & 0.0567 \\
\hline \multicolumn{8}{|c|}{$\tilde{\alpha}=2 ; \tilde{\delta}=0.10 ; x=0.70 ; M=1.11 ; B=0.11$} \\
\hline$Z^{*}$ & $\begin{array}{c}0.91 \\
(0.85,0.99)\end{array}$ & $\begin{array}{c}0.50 \\
(0.34,0.98)\end{array}$ & $\begin{array}{c}2.00 \\
(1.51,50.0)\end{array}$ & $\begin{array}{c}-0.63 \\
(-1.61,-0.001)\end{array}$ & $\begin{array}{c}0.74 \\
(0.001,1.98)\end{array}$ & $\begin{array}{c}-0.16 \\
(-0.42,-0.00)\end{array}$ & 0.0940 \\
\hline$Z^{P}$ & $\begin{array}{c}0.98 \\
(0.92,0.99)\end{array}$ & $\begin{array}{c}0.46 \\
(0.40,0.54)\end{array}$ & $\begin{array}{c}1.85 \\
(1.67,2.17)\end{array}$ & $\begin{array}{c}-0.80 \\
(-1.13,-0.50)\end{array}$ & $\begin{array}{c}0.99 \\
(0.59,1.43)\end{array}$ & $\begin{array}{c}-0.21 \\
(-0.30,-0.12)\end{array}$ & 0.0568 \\
\hline
\end{tabular}

The estimated model is (5)

$$
\hat{\pi}_{t}-\rho \hat{\pi}_{t-1}=H_{1}(\varpi) \lambda(\beta, \theta) \hat{U}_{t}+\left[H_{2}(\varpi)-\rho H_{1}(\varpi)\right] \lambda(\beta, \theta) \hat{U}_{t-1}-\rho H_{2}(\varpi) \lambda(\beta, \theta) \hat{U}_{t-2}+e_{3, t} .
$$

The applied test is the AR-HAC test. Four lags are used in the Newey-West heteroskedasticity and autocorrelation-consistent covariance estimator. Hodges-Lehmann point estimates are reported with the corresponding $p$-value under the heading 'Max P-val', while $1 /(1-\theta)$ refers to the implied average duration of prices (in quarters). The numbers in parentheses reported underneath a parameter estimate correspond to the projection-based confidence interval for that parameter. Instrument sets are as follows: $Z^{*}$ includes the third and fourth lag of each of: inflation, marginal cost, the unemployment rate and the change in the real price of the non-produced good in the economy and productivity. $Z^{P}$ includes the instruments in $Z^{*}$ as well as the third and fourth lag of productivity. 
calibration. Our finding that indexation models can deliver reasonable confidence bands on $\theta$ does not, in contrast to Eichenbaum and Fisher's arguments, necessarily result from modeling capital as being firmspecific, nor from assuming that firms face a variable price elasticity of demand.

On question 2, and as Benati (2008) finds for the US, our inference on the indexation parameter implies that the backward looking NKPC term is not statistically close to zero (we find a lower bound of around 0.29 using the extra-model instruments and 0.40 with the model-specific instrument set). While the purely forward looking version of the model is thus rejected by the data, our estimated range for this parameter also conforms with studies such as Galí, Gertler, and Lopez-Salido (2005) where rule-of-thumb hypotheses are used as an alternative to indexation. ${ }^{16}$

On question 3, we find firm statistical support for full indexation, a point worth noting since it was assumed in Eichenbaum and Fisher (2007).

On question 4, we find that both models that we considered can deliver a correctly signed and significant coefficient on the time $t$ unemployment term. This result is however highly sensitive to instrument choice (rather than to calibration). The same observation holds for the marginal cost term in the indexation model, and for the coefficients on unemployment lags in model (5). In contrast, the coefficient on the measure for the non-produced good in the economy is correctly signed and significant, with all calibrations and instrument sets considered.

On question 5, our estimations suggest a fairly high persistence measure for the productivity shock, which implies a fairly high extent of inflation inertia. A range consistent with the hypothesized model is obtained, yet the fact that we cannot refute the boundary value of 0.99 for $\rho$ calls for further work on modeling the productivity process. Admittedly, Blanchard and Gali propose the AR(1) process as a motivating illustrative case [rather than a fundamental modeling premise], so in this regard, our results suggest that the model holds promise. However we do not aim to abstract from the instrument sensitivity problem that seems as serious in this model as with the indexation based one.

Finally, turning to question 6, on referring our estimates to the hybrid gap-based expression underlying (3), we find that it is possible to firmly rule out the fully forward-looking model. Furthermore, as with the indexation-based NKPC, estimates of the backward looking term are not statistically close to zero. In fact, when $\mu=1.00$ and $v=0.33$, confidence sets for this term are close to the estimate ranges obtained with the indexation model. The lower bound is higher (exceeding 0.45) when $\mu=0.50$ and $v=0.05$.

Taken collectively, our results suggest that the data can actually reveal useful information via the NKPC, provided instrumentation is not strictly limited-information based. Indeed, when the expanded instrument set (including lags of the driving variables of all considered models in addition to model-specific endogenous variables) is used, we find that the examined models can deliver: (i) confidence bounds on the Calvo parameter that imply plausible inertia in price setting behavior; (ii) significant and correctly signed estimates of the driving variables so that the underlying NKPCs appear to fit the data; and (iii) estimates of structural persistence that are quite far from zero.

Substantial differences in the results obtained with the different instrument sets regarding the precision of price duration measures as well as of forcing variables illustrate the limits of testing models that require

\footnotetext{
${ }^{16}$ Note that we do not take a stance on the structural stability issue also discussed by Benati (2008), given that our study focuses on the post-1980 sample.
} 
a fair amount of calibration (particularly in a single-equation context) and in the absence of theory-based guidance in the selection of instruments. On balance, we find that a few key features of the examined NKPC seem invariant to such problems, at least for the instruments and calibrations considered. These include in particular the statistically and economically non-zero backward looking behavior.

The above cited identification-robust estimations of the NKPC (including our own previous work on such models) have so far delivered rather pessimistic verdicts on various popular models. Our results show that such conclusions are not necessarily warranted, although instrument-sensitivity issues remain. In this regard, we find that limiting the set of instruments to lagged values of only the variables which appear in the equation of interest can lead to substantial precision losses, even in the context of a limited-information analysis. ${ }^{17}$ In the present paper, lags of the driving variables from the competing models we analyzed provided natural off-model instruments. Efforts in such directions may be worth pursuing in empirical work on the NKPCs.

\section{Conclusion}

As econometric methods evolved in the last decade, empirical tests of sticky-price NKPCs suggest that available models do not fare well when taken to the data. In practice, the profession acknowledges that such models are imperfect and that analysts must make astute choices on the features of the models they hope to capture from the data. In this paper we provide evidence on the empirical worth of sticky-price NKPCs along these lines.

We estimate four illustrative structural equations allowing for indexation-based or wage-rigidity-based persistence and focus on assessing the precision of the structural measure of average price duration in the economy based on the Calvo parameter. To do so, we take seriously the fact that the specifications under consideration are hard to identify from available data, that macro-data is scarce, and that calibration of some parameters, error-in-variables, and weak-instruments concerns are unavoidable.

Without taking a stance on the relative statistical fit of the considered models, we show that the two categories of models can deliver: (i) reasonable and economically sound confidence bounds on the Calvo parameter that line up with micro-based evidence, and (ii) convincing answers to related substantive questions on the role of marginal cost or current and lagged unemployment, as well as on the role of lagged inflation. We also find that results are nonetheless sensitive to the choice of instruments and to calibration.

Finally, in view of our finding that strictly-limited-information based econometric approaches can be somewhat restrictive, assessing NKPC equations as part of a system is a worthy research objective.

\footnotetext{
${ }^{17}$ Indeed, even with large dynamic stochastic general equilibrium systems, reliance on off-model data is not unsual; see for example Consolo, Favero and Paccagnini (2009) and the references therein.
} 


\section{References}

Andrews, D.W.K., M.J. Moreira, and J.H. Stock. 2006. "Optimal Two-Sided Invariant Similar Tests for Instrumental Variables Regression.” Econometrica 74: 715-752.

Ball, L. 1994. “Credible Disinflation with Staggered Price-Setting.” American Economic Review 84: 282-89.

Beaulieu, M.C., J.M. Dufour, and L. Khalaf. 2008. "Finite Sample Multivariate Tests of Asset Pricing Models with Coskewness." Computational Statistics and Data Analysis forthcoming.

Benati, L. 2008. "Investigating Inflation Persistence across Monetary Regimes." Quarterly Journal of Economics 123: 1005-60.

- 2009. Are Intrinsic Inflation Persistence Models Structural in the Sense of Lucas. Technical report, European Central Bank Working paper No 1038.

Bils, M. and P. Klenow. 2004. "Some Evidence on the Importance of Sticky Prices." Journal of Political Economy 112: 947-85.

Blanchard, O. and J. Gali. 2007. "Real Wage Rigidities and the New Keynesian Model." Journal of Money, Credit and Banking 39: 35-65.

— 2009. "Labor Markets and Monetary Policy: A New Keynesian Model with Unemployment." American Economic Journal - Macroeconomics forthcoming.

Boivin, J. and M. Giannoni. 2006. "Has Monetary Policy Become More Effective?" The Review of Economics and Statistics 88(3): 445-62.

Bolduc, D., L. Khalaf, and E. Moyneur. 2008. "Identification-Robust Simulation-Based Inference in Joint Discrete/Continuous Models for Energy Markets.” Computational Statistics and Data Analysis 52: 31483161.

Calvo, G. 1983. "Staggered Prices in a Utility-Maximizing Framework." Journal of Monetary Economics 12: 383-98.

Canova, F. and L. Sala. 2009. "Back to Square One: Identification Issues in DSGE Models." Journal of Monetary Economics 54: 431-49.

Chari, V., P. Kehoe, and E. McGrattan. 2000. "Sticky Price Models of the Business Cycle: Can the Contract Multiplier Solve the Persistence Problem?" Econometrica 68(5): 1151-1180.

Chaudhuri, S. and E. Zivot. 2008. A New Method of Projection-Based Inference in GMM with Weakly Identified Nuisance Parameters. Technical report, University of Washington.

Christiano, L., M. Eichenbaum, and M. Evans. 2005. "Nominal Rigidities and the Dynamic Effects of a Shock to Monetary Policy." Journal of Political Economics 113: 1-45. 
Consolo, A., C.A. Favero, and A. Paccagnini. 2009. "On the Statistical Identification of DSGE Models." Journal of Econometrics 150: 99-115.

Danthine, J.P. and A. Kurmann. 2004. "Fair Wages in a New Keynesian Model of the Business Cycle." Review of Economic Dynamics 7: 107-42.

Del Negro, M. and F. Schorfheide. 2005. "Policy Predictions if the Model Does Not Fit." Journal of the European Economic Association 3(2-3): 434-43.

- 2006. "How good is what you've got? DSGE-VAR as a toolkit for evaluating DSGE models." Economic Review, Federal Reserve Bank of Atlanta Q2: 21-37.

Del Negro, M., F. Schorfheide, F. Smets, and R. Wouters. 2007. "On the Fit of New Keynesian Models." Journal of Business and Economic Statistics 25: 123-43.

Doko-Tchatoka, F. and J.M. Dufour. 2008. "Instrument endogeneity and identification-robust tests: some analytical results.” Journal of Statistical Planning and Inference 138: 2649-2661.

Dufour, J.M. 1997. "Some Impossibility Theorems in Econometrics, with Applications to Structural and Dynamic Models." Econometrica 65: 1365-89.

- 2003. "Identification, Weak Instruments and Statistical Inference in Econometrics." Canadian Journal of Economics 36(4): 767-808.

Dufour, J.M. and J. Jasiak. 2001. "Finite Sample Limited Information Inference Methods for Structural Equations and Models with Generated Regressors.” International Economic Review 42: 815-43.

Dufour, J.M., L. Khalaf, and M. Kichian. 2006. "Inflation dynamics and the New Keynesian Phillips Curve: an identification robust econometric analysis." Journal of Economic Dynamics and Control 30: 17071728.

. 2008. "Structural Multi-Equation Macroeconomic Models: Identification-Robust Estimation and Fit.” Working Paper, McGill University.

Dufour, J.M. and M. Taamouti. 2005. "Projection-Based Statistical Inference in Linear Structural Models with Possibly Weak Instruments.” Econometrica 73: 1351-1365.

—. 2007. "Further Results on Projection-Based Inference in IV Regressions with Weak, Collinear or Missing Instruments." Journal of Econometrics 139: 133-153.

Eichenbaum, M. and J. Fisher. 2007. "Estimating the Frequency of Price Re-optimization in Calvo-Style Models." Journal of Monetary Economics 54: 2032-47.

Fuhrer, J. and G. Moore. 1995. "Inflation Persistence." Quarterly Journal of Economics 110: 127-59.

Galí, J., M. Gertler, and J.D. Lopez-Salido. 2005. "Robustness of the Estimates of the Hybrid New Keynesian Phillips Curve.” Journal of Monetary Economics 52: 1107-18. 
Gali, J., D. Lopez-Salido, and J. Valles. 2003. "Technology Shocks and Monetary Policy: Assessing the Fed's Performance." Journal of Monetary Economics 50: 723-43.

Gali, J. and T. Monacelli. 2005. "Monetary Policy and Exchange Rate Volatility in a Small Open Economy." Review of Economic Studies 72: 707-34.

Hodges, J.L., Jr. and E.L. Lehmann. 1963. "Estimates of Location Based on Rank Tests.” Annals of Mathematical Statistics 34: 598-611.

—. 1983. "Hodges-Lehmann Estimators." In Encyclopedia of Statistical Sciences, Volume 3, edited by N.L. Johnson, S. Kotz, and C. Read, 642-45. New York: John Wiley \& Sons.

Hoogerheide, L.F., J.F. Kaashoek, and H.K. van Dijk. 2007. "On the shape of posterior densities and credible sets in instrumental variable regression models with reduced rank: An application of flexible sampling methods using neural networks." Journal of Econometrics 139(4): 154-180.

Jondeau, E. and J.G. Sahuc. 2008. "Optimal Monetary Policy in an Estimated DSGE Model of the Euro Area with Cross-Country Heterogeneity.” International Journal of Central Banking 4(2): 23-72.

Joseph, A.S. and J.F. Kiviet. 2005. "Viewing the relative efficiency of IV estimators in models with lagged and instantaneous feedbacks." Computational Statistics and Data Analysis 49: 417-444.

Kiviet, J.F. and J. Niemczyk. 2007. "The asymptotic and finite sample distributions of OLS and simple IV in simultaneous equations." Computational Statistics and Data Analysis 51: 3296-3318.

Kleibergen, F. 2002. "Pivotal Statistics for Testing Structural Parameters in Instrumental Variables Regression." Econometrica 70(5): 1781-1803.

— 2005. "Testing Parameters in GMM Without Assuming that They Are Identified." Econometrica 73: $1103-1123$.

Kleibergen, F. and S. Mavroeidis. 2009. "Weak Instrument Robust Tests in GMM and the New Keynesian Phillips Curve." Journal of Business and Economic Statistics forthcoming.

Klenow, P. and O. Kryvtsov. 2008. "State-Dependent or Time-Dependent Pricing: Does It Matter for Recent U.S. Inflation?” Quarterly Journal of Economics 123: 863-904.

Krause, M., D. Lopez-Salido, and T. Lubik. 2008. "Inflation dynamics with search frictions: A structural econometric analysis.” Journal of Monetary Economics 55(5): 892-916.

Lubik, T. and F. Schorfheide. 2007. "Do Central Banks Respond to Exchange Rate Movements? A Structural Investigation.” Journal of Monetary Economis 54: 1069-87.

Ma, A. 2002. "GMM Estimation of the New Keynesian Phillips Curve." Economics Letters 76: 411-17.

Mankiw, G. and R. Reis. 2002. "Sticky Information vs. Sticky Prices: A Proposal to Replace the New Keynesian Phillips Curve." Quarterly Journal of Economics 117: 1295-328. 
Mavroeidis, S. 2004. "Weak identification of forward-looking models in monetary economics." Oxford Bulletin of Economics and Statistics 66: 609-635.

- 2005. "Identification issues in forward-looking models estimated by GMM with an application ot the Phillips curve." Journal of Money, Credit and Banking 37: 421-449.

Nason, J. and G. Smith. 2008. "Identifying the New Keynesian Phillips Curve." Journal of Applied Econometrics 23: 525-51.

Roberts, J. 1997. “Is Inflation Sticky?” Journal of Monetary Economics 39: 173-96.

Rotemberg, J. and M. Woodford. 1997. "An Optimization-Based Econometric Framework for the Evaluation of Monetary Policy.” NBER Macroeconomics Annual 12: 297-46.

Sbordone, A. 2007. "Inflation Persistence: Alternative Interpretations and Policy Implications." Journal of Monetary Economics 54: 1311-39.

Sbordonne, A. 2002. "Prices and Unit Labor Costs: A New Test of Price Stickiness." Journal of Monetary Economics 49: 265-92.

Sims, C. 2007. "On the Fit of New Keynesian Models: Comment." Journal of Business and Economic Statistics 25: 152-4.

Smets, F. and R. Wouters. 2003. "An Estimated Stochastic General Equilibrium Model of the Euro Area." Journal of the European Economic Association 1: 1123-75.

—. 2007. "Shocks and Frictions in US Business Cycles: A Bayesian DSGE Approach." American Economic Review 97(3): 587-606.

Staiger, D. and J.H. Stock. 1997. "Instrumental Variables Regression with Weak Instruments." Econometrica 65(3): 557-86.

Stock, J.H., J.H. Wright, and M. Yogo. 2002. "A Survey of Weak Instruments and Weak Identification in Generalized Method of Moments." Journal of Business and Economic Statistics 20(4): 518-29.

Walsh, C. 2005. "Labor Market Search, Sticky Prices, and Interest Rate Policies." Review of Economic Dynamics 8: 829-49.

Wang, J. and E. Zivot. 1998. "Inference on Structural Parameters in Instrumental Variables Regression with Weak Instruments." Econometrica 66(6): 1389-1404.

Woodford, M. 2003. Interest and Prices. Princeton, New Jersey: Princeton University Press.

Zivot, E., R. Startz, and C.R. Nelson. 1998. "Valid Confidence Intervals and Inference in the Presence of Weak Instruments." International Economic Review 39: 1119-44. 


\section{Appendix}

\section{A Calibration}

For a full description of the models used, we refer the reader to the original papers. In this section, we explain the calibrated parameters that appear in the various NKPC equations.

For the indexation model (1), $\varpi=(\zeta, \epsilon, \xi, \psi, \delta)^{\prime}$ is defined as follows. $\epsilon$ represents the per cent change in the elasticity of demand for a given intermediate good due to a one per cent change in the relative price of the good at steady state, and $\zeta$ denotes the firm's steady state mark-up; conformably, the steady state elasticity of demand denoted $\eta$ is defined such that $\zeta=\eta /(\eta-1)-1$. $\xi$ is defined as $\xi=\bar{\alpha} /(1-\bar{\alpha})$, where $\bar{\alpha}$ is the share of capital in the production function. $\psi$ is a positive capital adjustment cost parameter, and $\bar{\delta}$ is defined such that the elasticity of the investment-to-capital ratio with respect to Tobin's $q$ (evaluated at steady-state) is given by $1 /(\bar{\delta} \psi)$. In this setting,

$$
\begin{aligned}
A(\varpi) & =1 /(\zeta \epsilon+1) \\
D(\beta, \theta, \varpi) & =\frac{\left(1-\beta \theta \kappa_{1}\right)}{(1+\eta \xi A(\varpi))\left(1-\beta \theta \kappa_{1}\right)+\xi A(\varpi) \beta \theta \kappa_{2}},
\end{aligned}
$$

where $\kappa_{1}$ and $\kappa_{2}$ are the solutions of the 3-equation system that solves for $\kappa_{1}, \kappa_{2}$ and $\nu$ subject to the constraint that $\left|\kappa_{1}\right|<1$, given by:

$$
\begin{aligned}
1-\left[\phi+(1-\theta \nu)\left(\beta \kappa_{2}-\Xi\right)\right] \kappa_{1}+\beta \kappa_{1}^{2} & =0 \\
\Xi \theta+\left[\phi-\beta\left(\theta+\kappa_{1}\right)-(1-\theta) \Xi \nu\right] \kappa_{2}+\beta(1-\theta) \nu \kappa_{2}^{2} & =0 \\
\frac{\xi A(\varpi)(1-\beta \theta)}{(1+\eta \xi A)\left(1-\beta \theta \kappa_{1}\right)+\xi A \beta \theta \kappa_{2}}-\nu & =0
\end{aligned}
$$

with

$$
\begin{aligned}
\Xi & =(1-\beta(1-\bar{\delta})) \eta \frac{1}{1-\bar{\alpha}} \frac{1}{\psi} \\
\phi & =1+\beta+(1-\beta(1-\bar{\delta})) \frac{1}{1-\bar{\alpha}} \frac{1}{\psi} .
\end{aligned}
$$

Model (1) is estimated under each of the two hypotheses $A=D=1$, and $A<1, D<1$, having imposed all of the appropriate structural constraints as described in Section 2.1. With the latter hypothesis, and as in Eichenbaum and Fisher (2007), we calibrate the elasticity parameter to 33 and the $\zeta$ parameter to 10 so that $A=0.23$. For the firm-specific capital case $(D<1)$, adjustment costs intervene and, as in EichenbaumFisher, $\psi$ is calibrated to 3 . Finally, the subjective discount rate, $\beta$, is calibrated to 0.99 .

For model (3), $\varpi=(v, \mu)^{\prime}$ and

$$
B(\varpi)=(1-v) \mu, \quad G(\varpi)=v
$$

where $v$ is the share of the non-produced good in total output and $\mu$ is the slope of labor supply. As in the original study, we set the Frisch labor supply elasticity, $\mu$, to 1 , and for $v$ we consider a value of 0.33 in line with the Chari, Kehoe, and McGrattan (2000) study. The alternative calibration that we consider is a value 
of 0.50 for the $\mu$ parameter, and 0.05 for $v$, which is closer to the actual share of crude materials production in the US economy. As before, $\beta$ is set to 0.99 .

For model $(5), \varpi=(\tilde{\alpha}, \mathcal{M}, \mathcal{B}, \tilde{\delta}, x)^{\prime}$

$$
\begin{aligned}
H_{1}(\varpi) & =-\frac{\tilde{\alpha} \mathcal{M g}}{\tilde{\delta}(1-\bar{U})}, \\
H_{2}(\varpi) & =\frac{\tilde{\alpha} \mathcal{M B}\left(x^{\tilde{\alpha}}\right)(1-\tilde{\delta})(1-x)}{\tilde{\delta}(1-\bar{U})}, \\
H_{3}(\beta, \varpi) & =-\frac{1-(1-\beta(1-\tilde{\delta})) \mathcal{M B}\left(x^{\tilde{\alpha}}\right)}{(1-\beta \rho)} .
\end{aligned}
$$

In the above, $\tilde{\delta}$ is an exogenous separation rate in the labor market, $x$ is the job finding rate, $\tilde{\alpha}$ is a parameter related to hiring costs, $\mathcal{M}$ is the gross steady-state mark-up, defined as $\tilde{\epsilon} /(\tilde{\epsilon}-1)$ with $\tilde{\epsilon}$ being the elasticity of substitution, $\mathcal{B}$ is a parameter related to the level of hiring costs, and the steady-state unemployment rate is given by $\bar{U}=(\tilde{\delta}(1-x)) /(x+\tilde{\delta}(1-x))$. For our baseline calibration, we use the same values adopted by Blanchard and Gali (2009) for their simulation studies for the US and set $\tilde{\alpha}=1, \tilde{\delta}=0.12, x=0.70$, with $\mathcal{M}=1.20$ and $\mathcal{B}=0.11$. We also consider an alternative calibration for some of the parameters. In this case, we set $\tilde{\alpha}=2$ and $\tilde{\delta}=0.10$, obtaining a value of 1.11 for $\mathcal{M}$. The subjective discount rate, $\beta$, is again calibrated to 0.99 .

\section{B Methodology}

To set focus, consider the model in equation (1), reproduced here for convenience with each variable considered in deviation from its empirical mean:

$$
\hat{\pi}_{t}=\frac{\beta}{(1+\beta \nu)} \hat{\pi}_{t+1}+\frac{\nu}{(1+\beta \nu)} \hat{\pi}_{t-1}+\left[\frac{A(\varpi) D(\beta, \theta, \varpi)}{(1+\beta \nu)}\right] \lambda(\beta, \theta) \hat{s}_{t}+e_{1, t+1}
$$

where right hand side coefficients are non-linear functions of the deep parameters $\nu$ and $\theta$, conditional on the remaining parameters which will denote $\Omega=\left(\beta, \varpi^{\prime}\right)^{\prime}$. The latter are calibrated as is usually done in the literature. Our aim is to estimate $\nu$ and $\theta$. .

For presentation clarity, we express (1) as

$$
y_{t}=Y_{t}^{\prime} \Gamma+e_{1, t+1}
$$

where $y_{t} \equiv \hat{\pi}_{t}, Y_{t}=\left(\hat{\pi}_{t+1}, \hat{\pi}_{t-1}, \hat{s}_{t}\right)^{\prime}$,

$$
\Gamma(\nu, \theta \mid \Omega)=\left(\left(\frac{\beta}{(1+\beta \nu)}\right),\left(\frac{\nu}{(1+\beta \nu)}\right),\left(\left[\frac{A(\varpi) D(\beta, \theta, \varpi)}{(1+\beta \nu)}\right] \lambda(\beta, \theta)\right)\right)^{\prime}
$$

and where $\Gamma(. \mid$.$) refers to the three-dimensional function that links the "reduced form" parameters to the deep$ parameters (that we aim to estimate) conditional on the calibration. ${ }^{18}$ An instrument set, $Z_{t}$, of dimension $k \times 1$ is also available at time $t$.

\footnotetext{
${ }^{18}$ As may be checked from the equations (2) and (6) - (12), the $\Gamma(. \mid$.$) function is highly non-linear and requires solving the$ three-equation system (8)-(10) for each value of the couple $(\nu, \theta)$.
} 
To further simplify presentation, we adopt the following notation: $y$ is the $T$ dimensional vector of observations on $\hat{\pi}_{t}, Y$ is the $T \times 3$ matrix of observations on $\hat{\pi}_{t+1}, \hat{\pi}_{t-1}$ and $\hat{s}_{t}, Z$ is the $T \times k$ matrix of the instruments, and $u$ is the $T$ dimensional vector of error terms, so that (16) translates into

$$
y=Y \Gamma(\nu, \theta \mid \Omega)+u \text {. }
$$

In traditional estimation methodology, a point estimate say $(\hat{\nu}, \hat{\theta})$ for the couple $(\nu, \theta)$ is found first, and confidence intervals for each of $\nu$ and $\theta$, each of level $1-\alpha$, are then constructed and often take the form

$$
\mathrm{Cl}(\theta ; \alpha)=\hat{\theta} \pm S E E(\hat{\theta}) \times \bar{c}_{\alpha}, \quad \mathrm{Cl}(\nu ; \alpha)=\hat{\nu} \pm S E E(\hat{\nu}) \times \bar{c}_{\alpha}
$$

where $S E E($.$) refers to the estimated standard error of the estimate and \bar{c}_{\alpha}$ is the asymptotic critical point. The generalized Anderson-Rubin (GAR) identification-robust approach that is used in this paper proceeds in the opposite sense: first a confidence set of joint level $1-\alpha$ is constructed for the couple $(\nu, \theta)$, then a point estimate is found from within this set.

The confidence set is constructed numerically (for example, through a grid-search approach), sweeping the economically-meaningful values of $\nu$ and $\theta$ [while fixing $\Omega$ to its calibrated value]. For each possible values for $\nu$ and $\theta$, say $\nu_{0}$ and $\theta_{0}$, a specifically-designed test statistic is applied (namely, the GAR test statistic given below), and the associated $p$-value is calculated (see below). Collecting those $\left(\nu_{0}, \theta_{0}\right)$ choices for which the $p$-values are greater than a level $\alpha$ yields a joint confidence region with level $1-\alpha$, which we denote for further reference, $\operatorname{GAR}((\nu, \theta) \mid \Omega ; \alpha)$. This is also known as 'inverting' at level $\alpha$, the GAR test associated with the null hypothesis

$$
H_{0}\left(\nu_{0}, \theta_{0} \mid \Omega\right): \nu=\nu_{0}, \quad \theta=\theta_{0}, \quad[\text { for a given } \Omega]
$$

where $\nu_{0}$ and $\theta_{0}$ are known values. ${ }^{19}$

To understand the latter definition, observe that the intervals $\mathrm{Cl}(. ; \alpha)$ in (18) actually 'invert', at level $\alpha$, for each of $\nu$ and $\theta$, the t-statistics

$$
\mathrm{t}(\hat{\theta})=\frac{\left|\hat{\theta}-\theta_{0}\right|}{S E E(\hat{\theta})} ; \quad \mathrm{t}(\hat{\nu})=\frac{\left|\hat{\nu}-\nu_{0}\right|}{S E E(\hat{\nu})}
$$

leading to two sets each with a $1-\alpha$ level. In contrast, when we proceed by collecting the $(\nu, \theta)$ combinations that are not rejected at level $\alpha$ by the GAR test, the associated region $\operatorname{GAR}((\nu, \theta) \mid \Omega ; \alpha)$ has a joint $1-\alpha$ level, that is, its probability to cover the true couple $(\nu, \theta)$ is at least $1-\alpha$.

Perhaps more importantly, the commonly used forms for the $t(\hat{\theta})$ and $t(\hat{\nu})$ statistics are fundamentally inappropriate since they (that is, the formula for $S E E($.$) as well as the associated central limit theory leading$ to the $\bar{c}_{\alpha}$ cutoffs) are often derived assuming full identification. Because such asymptotics do not account for the possibility of weak identification, they are fundamentally inaccurate; in fact, the above cited econometric literature has shown that if traditional GMM-type theory is applied, the coverage associated with each of $\mathrm{Cl}(. ; \alpha)$ may deviate arbitrarily from the assumed level $\alpha$. That is, its probability to cover the parameter value may be much lower than $1-\alpha$. In contrast, the GAR test does not require identification and will not suffer from such problems.

\footnotetext{
${ }^{19}$ As may become clear below, $\Omega$ is fixed though not tested.
} 
Moving from the joint region $\operatorname{GAR}((\nu, \theta) \mid \Omega ; \alpha)$ to individual confidence intervals for each of $\nu$ and $\theta$ is achieved by projecting the latter region, i.e. by computing, in turn, the smallest and largest values for each parameter included in this region. A point estimate can also be obtained from the joint confidence set. This corresponds to the model that is most compatible with the data, or, alternatively, that is least-rejected, and is given by the vector of parameter values with the largest $p$-value. The point estimate is thus the so-called Hodges-Lehmann estimate (see Hodges and Lehmann (1963); Hodges and Lehmann (1983)).

So let us now present the GAR test that we invert, and explain why it does not require full identification. The GAR procedure uses a simple artificial regression that translates the test problem into one that no longer faces endogeneity issues, but that nonetheless preserves the model's structural assumptions. For each combination for $\nu_{0}$ and $\theta_{0}$ [given $\Omega$ ], the artificial regression proceeds as follows. The $\Gamma(\nu, \theta \mid \Omega)$ function is applied $^{20}$ in order to obtain $\Gamma\left(\nu_{0}, \theta_{0} \mid \Omega\right)$ leading to

$$
\hat{\pi}_{t}^{*}\left(\nu_{0}, \theta_{0} \mid \Omega\right)=\hat{\pi}_{t}-\left(\hat{\pi}_{t+1}, \hat{\pi}_{t-1}, \hat{s}_{t}\right)^{\prime} \Gamma\left(\nu_{0}, \theta_{0} \mid \Omega\right) \Leftrightarrow y^{*}\left(\nu_{0}, \theta_{0} \mid \Omega\right)=y-Y \Gamma\left(\nu_{0}, \theta_{0} \mid \Omega\right)
$$

and the artificial regression, denoted the GAR regression:

$$
y^{*}\left(\nu_{0}, \theta_{0} \mid \Omega\right)=Z \Pi^{*}+u^{*}
$$

If the null hypothesis (19) that sets $\nu=\nu_{0}$ and $\theta=\theta_{0}$ is true, then the following hypothesis is also true:

$$
H_{0}^{*}\left(\nu_{0}, \theta_{0} \mid \Omega\right): \Pi^{*}=0
$$

Hence testing for (22) in the context of (21) provides a test of (19) in the original model (17). The test carried out in this form fits into a perfectly regular regression framework and thus does not require identification.

To allow for departures from the i.i.d. error hypothesis, we use a Wald-type test statistic with NeweyWest autocorrelation-consistent covariance estimator. For our considered coefficients it is given by:

$$
\begin{gathered}
A R-\operatorname{HAC}\left(\nu_{0}, \theta_{0} \mid \Omega\right)=y^{*}\left(\nu_{0}, \theta_{0} \mid \Omega\right)^{\prime} Z \widehat{Q}\left(\nu_{0}, \theta_{0} \mid \Omega\right)^{-1} Z^{\prime} y^{*}\left(\nu_{0}, \theta_{0} \mid \Omega\right), \\
\widehat{Q}\left(\nu_{0}, \theta_{0} \mid \Omega\right)=\frac{1}{T} \sum_{t=1}^{T} \widehat{u}_{t}\left(\nu_{0}, \theta_{0} \mid \Omega\right)^{2} Z_{t} Z_{t}^{\prime} \\
+\frac{1}{T} \sum_{l=1}^{L} \sum_{t=l+1}^{T} w_{l} \widehat{u}_{t}\left(\nu_{0}, \theta_{0} \mid \Omega\right) \widehat{u}_{t-l}\left(\nu_{0}, \theta_{0} \mid \Omega\right)\left(Z_{t} Z_{t-l}^{\prime}+Z_{t-l} Z_{t}^{\prime}\right), \\
w_{l}=1-\frac{l}{L+1},
\end{gathered}
$$

where $\widehat{u}_{t}\left(\nu_{0}, \theta_{0} \mid \Omega\right)$ is the OLS residual associated with regression (21), and $L$ is the number of allowed lags. A $p$-value [denoted $\left.p_{H A C}\left(\nu_{0}, \theta_{0} \mid \Omega\right)\right]$ is next calculated by referring $A R$ - $\operatorname{HAC}\left(\nu_{0}, \theta_{0}\right)$ to the $\chi^{2}(k)$ cut-off. Then the point estimates correspond to:

$$
\left(\hat{\nu}_{G A R}, \hat{\theta}_{G A R}\right)=\arg \max _{\left(\nu_{0}, \theta_{0}\right)}\left\{p_{H A C}\left(\nu_{0}, \theta_{0} \mid \Omega\right)\right\} .
$$

\footnotetext{
${ }^{20}$ It is worth reemphasizing that we solve the system (8)-(10) for each value we sweep.
} 
If, given the data, no parameter values are compatible with the model, that is if all swept $\left(\nu_{0}, \theta_{0}\right)$ are rejected at level $\alpha$ so the confidence set is empty, or alternatively, when

$$
\max _{\left(\nu_{0}, \theta_{0}\right)}\left\{p_{H A C}\left(\nu_{0}, \theta_{0} \mid \Omega\right)\right\}<\alpha \Leftrightarrow \operatorname{GAR}((\nu, \theta) \mid \Omega ; \alpha)=\varnothing
$$

then the econometric model is rejected at level $\alpha$; in other words, the method has a built-in J-type test. On the other hand, if a parameter is simply not identifiable given the data, then, for every admissible value of this parameter, the model cannot be rejected. Accordingly, all of these values should be found in the confidence set for this parameter estimate, which, in the limit, could be unbounded. ${ }^{21}$

\footnotetext{
${ }^{21}$ As argued above, because of asymptotic irregularities, the intervals $\mathrm{Cl}(. ; \alpha)$ in (18) would not yield such diffuse intervals if the underlying parameter is not identified. Rather, one is likely to see very tight confidence intervals that are focused on "wrong" values. So intervals as is (18) would grossly understate estimation uncertainty, and would fail to cover the true parameter value (which, in view of the interval tightness, will go unnoticed).
} 